\title{
Observations of NO in the upper mesosphere and lower thermosphere during ECOMA 2010
}

\author{
J. Hedin ${ }^{1}$, M. Rapp ${ }^{2, *}$, M. Khaplanov ${ }^{1}$, J. Stegman ${ }^{1}$, and G. Witt ${ }^{1}$ \\ ${ }^{1}$ Department of Meteorology, Stockholm University, Stockholm, Sweden \\ ${ }^{2}$ Leibniz-Institute for Atmospheric Physics, Kühlungsborn, Germany \\ * now at: Deutsches Zentrum für Luft- und Raumfahrt, Institut für Physik der Atmosphäre, Oberpfaffenhofen, Germany
}

Correspondence to: J. Hedin (jonash@misu.su.se)

Received: 31 July 2012 - Revised: 24 October 2012 - Accepted: 6 November 2012 - Published: 28 November 2012

\begin{abstract}
In December 2010 the last campaign of the German-Norwegian sounding rocket project ECOMA (Existence and Charge state Of Meteoric smoke particles in the middle Atmosphere) was conducted from Andøya Rocket Range in northern Norway $\left(69^{\circ} \mathrm{N}, 16^{\circ} \mathrm{E}\right)$ in connection with the Geminid meteor shower. The main instrument on board the rocket payloads was the ECOMA detector for studying meteoric smoke particles (MSPs) by active photoionization and subsequent detection of the produced charges (particles and photoelectrons). In addition to photoionizing MSPs, the energy of the emitted photons from the ECOMA flash-lamp is high enough to also photoionize nitric oxide (NO). Thus, around the peak of the NO layer, at and above the main MSP layer, photoelectrons produced by the photoionization of NO are expected to contribute to, or even dominate above the main MSP-layer, the total measured photoelectron current. Among the other instruments on board was a set of two photometers to study the $\mathrm{O}_{2}\left(b^{1} \Sigma_{g}^{+}-X^{3} \Sigma_{g}^{-}\right)$Atmospheric band and $\mathrm{NO}_{2}$ continuum nightglow emissions. In the absence of auroral emissions, these two nightglow features can be used together to infer NO number densities. This will provide a way to quantify the contribution of NO photoelectrons to the photoelectron current measured by the ECOMA instrument and, above the MSP layer, a simultaneous measurement of NO with two different and independent techniques. This work is still on-going due to the uncertainties, especially in the effort to quantitatively infer NO densities from the ECOMA photoelectron current, and the lack of simultaneous measurements of temperature and density for the photometric study. In this paper we describe these two techniques to infer NO densities and discuss the uncertainties. The peak NO number density inferred from the two photometers on as-
\end{abstract}

cent was $3.9 \times 10^{8} \mathrm{~cm}^{-3}$ at an altitude of about $99 \mathrm{~km}$, while the concentration inferred from the ECOMA photoelectron measurement at this altitude was a factor of 5 smaller.

Keywords. Atmospheric composition and structure (Airglow and aurora; Middle atmosphere - composition and chemistry; Instruments and techniques)

\section{Introduction}

\subsection{Nitric oxide in the middle atmosphere}

The presence of nitric oxide (NO) in the upper atmosphere was first suggested by Kaplan (1939) and later confirmed by Barth (1964). It has since then been a species of major interest for the aeronomy of the middle atmosphere. NO has a low ionization threshold and controls the ion composition of the ionospheric E-region. In addition, its photoionization by direct solar (and geocoronal) Lyman- $\alpha$ radiation creates the ionospheric D-region (Nicolet, 1945). NO is also an important source of radiative cooling as it emits efficiently in the infrared at $5.3 \mu \mathrm{m}$ (e.g. Kockarts, 1980; López-Puertas and Taylor, 2001). As for neutral chemistry in the middle atmosphere, $\mathrm{NO}$ is a major player in determining the odd-oxygen budget. Altogether, this makes NO an important player in the energy balance and temperature structure of the upper mesosphere and lower thermosphere.

$\mathrm{NO}$ is produced in the lower thermosphere through the interaction of solar radiation and auroral particles with the atmospheric constituents in this part of the atmosphere (for details see e.g. Strobel, 1971; Thorne, 1980; Rusch et al., 1981; Barth, 1992; Bailey et al., 2002). In short, the primary

Published by Copernicus Publications on behalf of the European Geosciences Union. 
production mechanism in the lower thermosphere, at the peak of the NO layer around $110 \mathrm{~km}$, is the reaction of excited atomic nitrogen, $\mathrm{N}\left({ }^{2} \mathrm{D}\right)$, with $\mathrm{O}_{2}$. At higher altitudes, above $\sim 140 \mathrm{~km}$, the dominant production mechanism is the strongly temperature dependent reaction of ground state atomic nitrogen, $\mathrm{N}\left({ }^{4} \mathrm{~S}\right)$, with $\mathrm{O}_{2}$. Both reactions occur in the atmosphere but the reaction of $\mathrm{N}\left({ }^{2} \mathrm{D}\right)$ with $\mathrm{O}_{2}$ is much faster at the temperatures in the lower thermosphere. Loss mechanisms are the reactions with $\mathrm{N}\left({ }^{4} \mathrm{~S}\right)$ (primary), $\mathrm{O}_{2}^{+}$or through photodissociation by solar UV radiation. $\mathrm{N}\left({ }^{2} \mathrm{D},{ }^{4} \mathrm{~S}\right)$ is produced in the reaction of $\mathrm{N}_{2}^{+}$with $\mathrm{O}$, through impact dissociation of $\mathrm{N}_{2}$ by energetic electrons (auroral secondary electrons and fast photoelectrons due to solar soft X-rays) and through dissociative recombination of $\mathrm{NO}^{+}$or $\mathrm{N}_{2}^{+}$with ambient electrons. This results in a production of $\mathrm{NO}$ at high latitudes that is mostly under geomagnetic control and thus highly variable in space and time. At lower latitudes the production is mostly under solar control showing clear 27-day and 11-year variations (Barth, 1992), although Joule heating events connected to geomagnetic storms can result in an increase in the lower thermosphere also at low latitudes (Barth et al., 2009).

The diffusion transport lifetime of NO in the lower thermosphere is about one day, while the chemical lifetime in sunlit conditions is approximately 0.8 day (19h) (Barth, 1992; Barth et al., 2001). Since the solar energy input into the atmosphere varies throughout the day, the amount of NO at one time is effectively a measure of the level of solar irradiance and auroral energy deposition over the previous day. Especially at winter polar latitudes NO has a long chemical lifetime and can be efficiently transported downward in the nighttime winter polar vortex into the stratosphere where it can affect ozone-related chemistry (e.g. Solomon et al., 1982; Siskind et al., 2000; Randall et al., 2009; Funke et al., 2005). This is a prominent example of downward influence in the middle atmosphere.

Another important reaction cycle is the conversion between $\mathrm{NO}$ and $\mathrm{NO}_{2}$ (or recycling of the $\mathrm{NO}_{\mathrm{x}}$ species) in the middle atmosphere, including the $\mathrm{NO}+\mathrm{O}$ "air afterglow" reaction

$\mathrm{NO}+\mathrm{O}(+\mathrm{M}) \rightarrow \mathrm{NO}_{2}(+\mathrm{M})+h v$.

This results in a broad emission feature in the Earth's visible and near infrared nightglow spectrum, the $\mathrm{NO}_{2}$ nightglow continuum. This emission can be used, together with knowledge about the local $\mathrm{O}$ concentration and in the absence of auroral emissions, to infer NO number densities in the upper mesosphere and lower thermosphere region (Sharp, 1978; Witt et al., 1981; McDade et al., 1986a; von Savigny et al., 1999; Gattinger et al., 2010; Enell et al., 2011; Sheese et al., 2011). An attempt to do this was made by adding a set of two photometers to each of the three payloads in the last campaign of the ECOMA project in December 2010. This approach is similar to the set of photometers described by Enell et al. (2011), but without the $\mathrm{N}_{2}^{+} 1$ st Neg. band auroral photometer. The reasons for adding the two nightglow photometers to the ECOMA payloads were twofold: (1) to try to quantify the contribution from NO photoelectrons to the photoelectron current measured by the ECOMA detector, and (2) to measure the NO abundance simultaneously with two independent techniques. Unfortunately only the first payload, launched in the early morning on 4 December (04:21 UT), gave useable photometer data. The ECOMA project is briefly described in the following section below, the measurements are presented in Sect. 2 and the results are discussed in Sect. 3.

\subsection{The ECOMA project}

The German-Norwegian ECOMA project (Existence and Charge state Of Meteoric smoke particles in the middle Atmosphere) was a set of nine sounding rockets in four campaigns launched from Andøya Rocket Range in northern Norway $\left(69^{\circ} \mathrm{N}, 16^{\circ} \mathrm{E}\right)$ from 2006 to 2010 . The aim of ECOMA was to study meteoric smoke particles (MSPs) in the middle atmosphere during different seasons and under various atmospheric conditions (Strelnikova et al., 2009; Rapp et al., 2010, 2012). MSPs are tiny nanometre sized particles that are thought to be formed through chemical conversion and subsequent re-condensation and coagulation of the meteoric material that originate from meteoroid ablation in the 70-120 km altitude (Rosinski and Snow, 1961; Hunten et al., 1980; Plane, 2003; Gabrielli et al., 2004; Megner et al., 2008). Estimates of the amount of meteoric material that enters the Earth's atmosphere each day vary from less than 10 to more than $100 \mathrm{t}$ (Love and Brownlee, 1993; Mathews et al., 2001; von Zahn, 2005). Indirect evidence of the existence of MSPs is available from measurements of heavy charge carriers from sounding rockets and incoherent scatter radar experiments (e.g. Rapp et al., 2007; Strelnikova et al., 2007; Fentzke et al., 2009). Despite the lack of knowledge, these MSPs have been suggested to play key roles in several mesospheric processes, such as the formation and evolution of mesospheric ice particles (i.e. noctilucent clouds and polar mesosphere summer echoes) (Rapp and Thomas, 2006), heterogeneous $\mathrm{HO}_{\mathrm{x}}$ chemistry (Summers et al., 2001), mesospheric metal chemistry (Plane, 2004), and the D-region charge balance (Rapp and Lübken, 2001). In addition, they are thought to be transported down into the stratosphere where they may take part in the formation of polar stratospheric clouds and, hence, are involved in the destruction of ozone during polar spring (Voigt et al., 2005). Accurate measurements of MSPs are thus of high importance.

The main instrument on the rocket payload was the ECOMA particle detector. It is essentially a Faraday cup similar to the one originally developed by Havnes et al. (1996) for detection of charged particles, combined with a Xenon flash lamp for active photoionization and photodetachment of neutral and negatively charged particles (Rapp and 
Strelnikova, 2009). In this way, the detector continuously measures the currents produced by the a-priori charged particles and, after each flash of the Xenon flash lamp, the currents produced by fast photoelectrons excited by the UV photons. The direct particle measurement is affected by aerodynamics, which results in an altitude and particle size dependent detection efficiency (Hedin et al., 2007; Strelnikova et al., 2009), while the photoelectron measurement is not. However, it can be contaminated by photoelectrons from the photoionization of other atmospheric constituents. The photons from the flash lamp have a broad spectrum with a minimum wavelength of $110 \mathrm{~nm}$, or maximum energy of $11.2 \mathrm{eV}$, which is enough to ionize, for example, $\mathrm{FeO}$, NO and $\mathrm{O}_{2}\left(a^{1} \Delta_{\mathrm{g}}\right)$ with ionization thresholds of 8.56, 9.25 and $11.1 \mathrm{eV}$, respectively. Photoelectrons from the ionization of $\mathrm{NO}$ are in fact expected to be a significant contribution to the measured signal at altitudes above $\sim 90-95 \mathrm{~km}$ (Strelnikova et al., 2009). In Sect. 2 below we present the measurements made by the photometers and the ECOMA detector and describe how to infer NO number densities from them.

\section{Measurements and results}

\subsection{NO from the photometric measurements}

The $\mathrm{NO}+\mathrm{O}$ air afterglow reaction that gives rise to the $\mathrm{NO}_{2}$ nightglow continuum is known to occur along two-body and three-body reaction paths simultaneously (e.g. Becker et al., 1972). At high altitudes (low pressure), the chemiluminescence is believed to arise solely from the two-body radiative recombination reaction:

$\mathrm{NO}+\mathrm{O} \stackrel{k_{1}^{\lambda}}{\longrightarrow} \mathrm{NO}_{2}+h v$,

where $k_{1}^{\lambda}$ is the bimolecular differential chemiluminescence rate coefficient for emission at wavelength $\lambda$. At low altitudes (high pressure), the three-body reaction involving the production of an electronically excited $\mathrm{NO}_{2}$ molecule is the major pathway:

$\mathrm{NO}+\mathrm{O}+\mathrm{M} \stackrel{k_{2}^{\lambda, M}}{\longrightarrow} \mathrm{NO}_{2}^{*}+M$,

$\mathrm{NO}_{2}^{*}+\mathrm{M} \stackrel{k_{q}^{\lambda, M}}{\longrightarrow} \mathrm{NO}_{2}+M$,

$\mathrm{NO}_{2}^{*} \stackrel{k_{r}^{\lambda}}{\longrightarrow} \mathrm{NO}_{2}+h v$

where $M$ denotes the third body $\left(\mathrm{N}_{2}\right.$ or $\left.\mathrm{O}_{2}\right), k_{2}^{\lambda, M}$ is the termolecular rate coefficient for the formation of a stabilised electronically excited $\mathrm{NO}_{2}$ molecule capable of emission at wavelength $\lambda$ with a transition probability $k_{r}^{\lambda} \cdot k_{q}^{\lambda, M}$ is the wavelength dependent combined electronic quenching and vibrational deactivation coefficient. The number densities of the third body at nightglow altitudes are such that neither of the two pathways dominates over the other. McDade
Table 1. Adopted parameters used in Eq. (4) for calculating $k^{\lambda}$, the total bimolecular rate coefficient for the $\mathrm{NO}_{2}$ chemiluminescence.

\begin{tabular}{ll}
\hline & \multicolumn{1}{c}{$\lambda=540 \mathrm{~nm}$} \\
\hline$k_{1}^{\lambda}$ & $1.0 \times 10^{-20}\left(\right.$ photons nm$\left.^{-1}\right) \mathrm{cm}^{3}$ molecule $^{-2} \mathrm{~s}^{-1}$ \\
$d_{\mathrm{N}_{2}}^{\lambda}$ & $2.8 \times 10^{-14} \mathrm{~cm}^{3}$ molecule $^{-1}$ \\
$d_{\mathrm{O}_{2}}^{\lambda}$ & $2.3 \times 10^{-14} \mathrm{~cm}^{3}$ molecule $^{-1}$ \\
$q_{\mathrm{N}_{2}}^{\lambda}$ & $2.8 \times 10^{-15} \mathrm{~cm}^{3}$ molecule $^{-1}$ \\
$q_{\mathrm{O}_{2}}^{\lambda}$ & $2.5 \times 10^{-15} \mathrm{~cm}^{3}$ molecule $^{-1}$ \\
\hline
\end{tabular}

et al. (1986a) defined a total effective bimolecular rate coefficient for the chemiluminescence based on the work of Becker et al. (1972), including the temperature dependence of the three-body reaction, $F_{3}(T)$, reported by Whytock et al. (1976) and the possible temperature dependence of the two-body reaction, $F_{2}(T)$, suggested by Sharp (1984), as

$k^{\lambda, M}=k_{1}^{\lambda}\left\{F_{2}(T)+d_{M}^{\lambda}[M] F_{3}(T) /\left(1+q_{M}^{\lambda}[M]\right)\right\}$,

$F_{2}(T)=\exp \{530(1 / 296-1 / T)\}$,

$F_{3}(T)=\exp \{584(1 / T-1 / 296)\}$.

The parameters $d_{M}^{\lambda}$ and $q_{M}^{\lambda}$ are associated with $k_{2}^{\lambda, M} / k_{1}^{\lambda}$ and $k_{q}^{\lambda, M} / k_{r}^{\lambda}$, respectively, and are listed (for $M=\mathrm{O}_{2}$ and $\mathrm{N}_{2}$ ) together with $k_{1}^{\lambda}$ in Table 1 for $\lambda=540 \mathrm{~nm}$ (from McDade et al., 1986a). The temperature dependence of the twobody reaction suggested by Sharp (1984) has not yet been confirmed and we will here, in accordance with McDade et al. (1986a) and von Savigny et al. (1999), define two cases for this temperature dependence: "case A" that does not include a temperature dependence (i.e. $F_{2}(T)=1$ ), and "case B" that does. The total effective bimolecular rate coefficient for the $\mathrm{NO}_{2}$ chemiluminescence can then be written as

$k^{\lambda}=k_{1}^{\lambda}\left\{F_{2}(T)+\frac{\left(d_{\mathrm{N}_{2}}^{\lambda}\left[\mathrm{N}_{2}\right]+d_{\mathrm{O}_{2}}^{\lambda}\left[\mathrm{O}_{2}\right]\right) e^{\left\{584\left(\frac{1}{T}-\frac{1}{296}\right)\right\}}}{\left(1+q_{\mathrm{N}_{2}}^{\lambda}\left[\mathrm{N}_{2}\right]+q_{\mathrm{O}_{2}}^{\lambda}\left[\mathrm{O}_{2}\right]\right)}\right\}$

and is plotted in Fig. 1 for the two cases. Unfortunately, neither the atmospheric density and temperature measurement by the CONE instrument on board the payload (due to instrument failure), nor the ground based lidar measurements (due to tropospheric cloudiness) provided useful data for input into Eq. (4). Instead, the atmospheric total density (and 


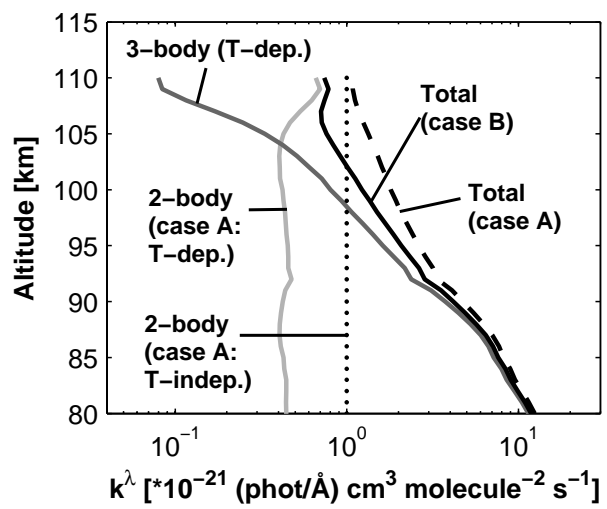

Fig. 1. The two-body, three-body and total effective rate coefficients for the $\mathrm{NO}_{2}$ chemiluminescence at around $540 \mathrm{~nm}$. The light grey profile is the temperature dependent two-body rate coefficient $\left(k_{1}^{\lambda} \cdot F_{2}(T)\right)$; the dotted line is the temperature independent twobody rate coefficient, i.e. $k_{1}^{\lambda}$; the dark grey profile is the temperature dependent three-body rate coefficient (essentially Eq. 4 with $F_{2}(T)=0$ ); the dashed black profile is the total effective bimolecular rate coefficient with no temperature dependence in the two-body reaction ("case A" in the text, i.e. Eq. 4 with $F_{2}(T)=1$ ); and the black profile is the total effective bimolecular rate coefficient with the temperature dependence in both the two- and three-body reactions ("case B" in the text).

the corresponding temperature) is taken from the SeptemberOctober climatology by Rapp et al. (2001). The change in atmosphere density and temperature between SeptemberOctober to the beginning of December is not expected to be larger than the typical variability. The sensitivity of the $\mathrm{NO}$ and $\mathrm{O}$ retrievals to changes in the atmospheric density and temperature is discussed later in this section. The $\mathrm{O}_{2}$ and $\mathrm{N}_{2}$ fraction of the total density is estimated from the volume mixing ratios for the two species given by the NRLMSISE-00 empirical atmospheric model (Picone et al., 2002) for the time of the launch.

If the $\mathrm{NO}+\mathrm{O}$ air afterglow reaction is the only process that results in an emission in the night sky around $540 \mathrm{~nm}$, the local $\mathrm{NO}$ concentration is related to the $\mathrm{NO}_{2}$ continuum volume emission rate, $V_{\text {Cont. }}$, and the local $\mathrm{O}$ number density as

$[\mathrm{NO}]=V_{\text {Cont. }} / k^{\lambda}[\mathrm{O}]$.

The $\mathrm{O}_{2}\left(b^{1} \Sigma_{g}^{+}-X^{3} \Sigma_{g}^{-}\right)$Atmospheric band (the $\mathrm{O}_{2}$ A-band) nightglow emission is directly related to the atomic oxygen abundance and can be used to derive the $\mathrm{O}$ number density (e.g. McDade et al., 1986b; Meriwether, 1989; Murtagh, 1989; Hedin et al., 2009). Atomic oxygen formed through $\mathrm{O}_{2}$ photolysis during the day recombines to form excited $\mathrm{O}_{2}$ molecules during the night. The $\mathrm{O}_{2}$ A-band emitting state is thought to form through an energy transfer mechanism from the precursor state (formed in the three-body recombination reaction) with $\mathrm{O}_{2}$ as the transfer agent. The volume emission
Table 2. Adopted rate coefficients and excitation parameters used in Eq. (6) for the retrieval of $\mathrm{O}$ from the measured $\mathrm{O}_{2}$ A-band nightglow emission. $\mathrm{C}^{\mathrm{O}}$ and $\mathrm{C}^{\mathrm{O}_{2}}$ are the excitation parameters derived empirically from the ETON data and describe the quenching of the precursor state by $\mathrm{O}$ and $\mathrm{O}_{2}$, respectively. All coefficients are in the usual units in terms of molecules, $\mathrm{cm}^{3}$, and seconds.

\begin{tabular}{ll}
\hline Coefficient & Value \\
\hline$k_{1}$ & $4.7 \times 10^{-33}(300 / \mathrm{T})^{2}$ \\
$k_{2}^{\mathrm{O}_{2}}$ & $4.0 \times 10^{-17}$ \\
$k_{2}^{\mathrm{N}_{2}}$ & $2.2 \times 10^{-15}$ \\
$k_{2}^{\mathrm{O}}$ & $8.0 \times 10^{-14}$ \\
$A_{1}$ & 0.079 \\
$A_{2}$ & 0.083 \\
$C^{\mathrm{O}_{2}}$ & $6.6 \pm 0.4$ \\
$C^{\mathrm{O}}$ & $19 \pm 2$ \\
\hline
\end{tabular}

rate of the $\mathrm{O}_{2}$ A-band at $761.9 \mathrm{~nm}$ can be expressed as

$V_{\mathrm{Aband}}=\frac{A_{1} \cdot k_{1}[\mathrm{O}]^{2} \cdot\left\{\left[\mathrm{O}_{2}\right]+\left[\mathrm{N}_{2}\right]\right\} \cdot\left[\mathrm{O}_{2}\right]}{\left\{A_{2}+k_{2}^{\mathrm{O}_{2}}\left[\mathrm{O}_{2}\right]+k_{2}^{\mathrm{N}_{2}}\left[\mathrm{~N}_{2}\right]+k_{2}^{\mathrm{O}}[\mathrm{O}]\right\} \cdot\left\{\mathrm{C}^{\mathrm{O}}\left[\mathrm{O}_{2}\right]+C^{\mathrm{O}}[\mathrm{O}]\right\}}$,

where $A_{1}$ is the $\mathrm{O}_{2}\left(b^{1} \Sigma_{g}^{+}\right)(0-0)$ band transition probability, $A_{2}$ is the inverse radiative lifetime of $\mathrm{O}_{2}\left(b^{1} \Sigma_{g}^{+}, v=0\right)$, $k_{1}$ is the temperature dependent rate coefficient for the threebody recombination of atomic oxygen, and $k_{2}^{\mathrm{O}_{2}}, k_{2}^{\mathrm{N}_{2}}$ and $k_{2}^{\mathrm{O}}$ are the rate coefficients for the quenching of $\mathrm{O}_{2}\left(b^{1} \Sigma_{g}^{+}\right)$by $\mathrm{O}_{2}, \mathrm{~N}_{2}$ and $\mathrm{O}$, determined from lab measurements. $C^{\mathrm{O}_{2}}$ and $C^{\mathrm{O}}$ are excitation parameters for the quenching of the precursor state by $\mathrm{O}_{2}$ and $\mathrm{O}$. These were derived empirically from the measurements in the ETON rocket campaign (Greer et al., 1986; McDade et al., 1986b). The values of the rate coefficients and excitation parameters to be used in Eq. (6) are listed in Table 2 and more details can be found in e.g. McDade et al. (1986b), Murtagh (1989) or Hedin et al. (2009). Equation (6) can be inverted to retrieve the $\mathrm{O}$ number density for input into Eq. (5).

For nightglow measurements (or airglow measurements in general) a filter photometer is positioned under the nose cone viewing along the rocket axis. The photometer consists of a photomultiplier tube, optics to focus the light on the photosensitive surface and to define a narrow field of view, and an interference filter that selects the wavelength range. For daytime measurements, a baffle system is added that prevents direct sunlight from reaching into the detector. During ascent, after the nose cone ejection, the photometer counts the incoming photons from the overhead column. When the rocket passes through the layer the measured photon flux drops 

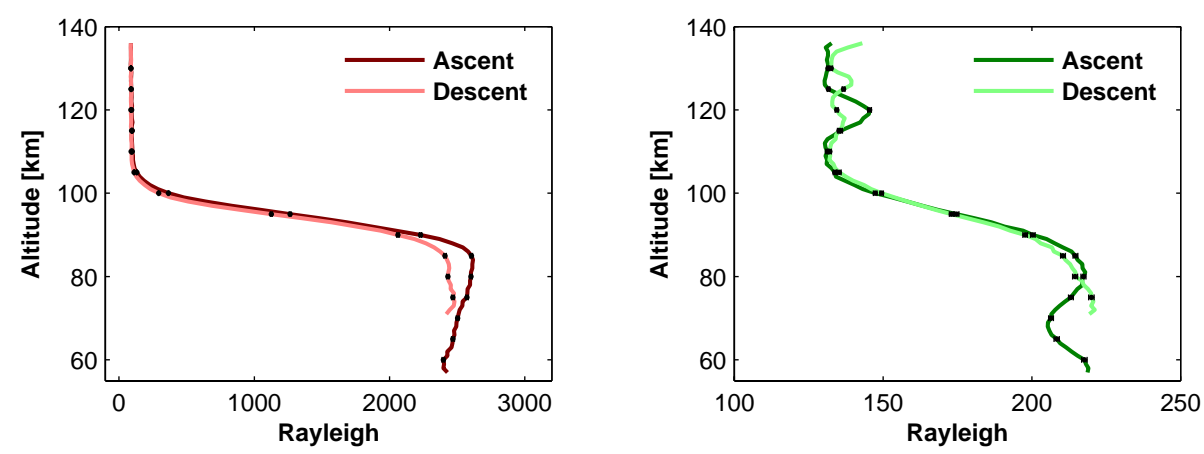

Fig. 2. The measured column emission in units of Rayleigh, $\mathrm{R}$ (the radiance in photons $\mathrm{cm}^{-2} \mathrm{str}^{-1} \mathrm{~s}^{-1}$ multiplied by $4 \pi \times 10^{-6}$ ), for the (0-0) band of the $\mathrm{O}_{2}$ A-band system centred at $761.9 \mathrm{~nm}$ (left panel) and the $\mathrm{NO}_{2}$ continuum at around $540 \mathrm{~nm}$ (right panel) as a function of altitude for both the ascent (darker colour) and descent (lighter colour) part of the flight. The profiles are interval averaged with $1 \mathrm{~km}$ vertical resolution and the error bars show the error of the mean. Note that the background sky emissions have not been subtracted (i.e. the signal

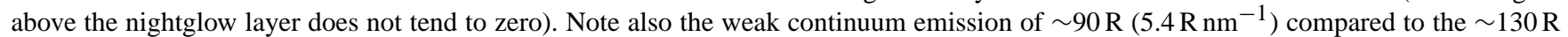
$\left(7.8 \mathrm{R} \mathrm{nm}^{-1}\right)$ background.
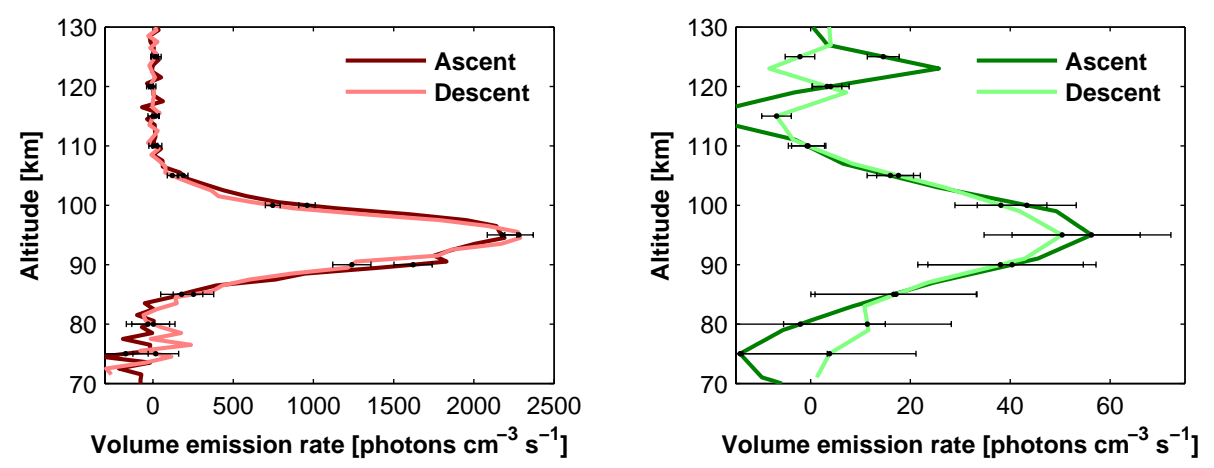

Fig. 3. The volume emission rates of the $\mathrm{O}_{2}$ Atmospheric band (left panel, $1 \mathrm{~km}$ resolution) and the $\mathrm{NO}_{2}$ continuum (right panel, $4 \mathrm{~km}$ resolution) nightglow emissions as determined from the photometric measurements on ECOMA7 (with the error bars showing the error of the mean).

and above the emission layer only background emissions are present (e.g. the zodiacal and galactic light). A profile can normally be obtained also on the descent part of the flight, since the payload will keep its attitude down to an altitude of about $70 \mathrm{~km}$ before it starts to tumble due to the increased atmospheric density. The measured photon flux is then translated to radiance using the pre-flight calibration, and corrected for attitude and converted to vertical profiles. The vertical profiles are then differentiated to yield the volume emission rate of the emitting layer as a function of altitude. The two photometers on board the ECOMA payloads monitored the (0-0) band nightglow emission of the $\mathrm{O}_{2}$ A-band system centred at $761.9 \mathrm{~nm}$ and the $\mathrm{NO}_{2}$ nightglow continuum in a wavelength region around $540 \mathrm{~nm}(16.6 \mathrm{~nm}$ filter full width at half maximum), respectively. Figure 2 shows the measured column emissions in units of Rayleigh, $\mathrm{R}$ (the radiance in photons $\mathrm{cm}^{-2} \mathrm{str}^{-1} \mathrm{~s}^{-1}$ multiplied by $\left.4 \pi \times 10^{-6}\right)$, for the $\mathrm{O}_{2}$ A-band (left panel) and the $\mathrm{NO}_{2}$ continuum (right panel) as a function of altitude for both the ascent (darker colour) and descent (lighter colour) part of the flight. The overhead radi- ances of the nightglow layers are $\sim 2.5 \mathrm{kR}$ for the total (0-0) band of the $\mathrm{O}_{2} \mathrm{~A}$-band system and $\sim 90 \mathrm{R}$, or $\sim 5.4 \mathrm{R} \mathrm{nm}^{-1}$, for the green nightglow continuum around $540 \mathrm{~nm}$. The profiles are interval averaged with $1 \mathrm{~km}$ vertical resolution and the error bars show the error of the mean. It should be noted that the $\mathrm{NO}_{2}$ continuum emission is very weak and that the background emissions from the galactic and zodiacal light in this wavelength region can be of the same order of magnitude (see Fig. 2). These background emissions are not constant but vary depending on which part of the night sky is in the field of view (Witt et al., 1981; Leinert et al., 1998).

The left panel in Fig. 3 shows the volume emission rate of the $\mathrm{O}_{2}$ A-band ( $1 \mathrm{~km}$ resolution), while the volume emission rate of the $\mathrm{NO}_{2}$ continuum (4 $\mathrm{km}$ resolution) is shown in the right panel (the darker profile in each of the two plots are from the ascent part of the flight) with the error bars showing the error of the mean. These two emission features can now be used to infer NO number densities in the upper mesosphere and lower thermosphere according to Eq. (5). The retrieved $\mathrm{O}$ profiles from the $\mathrm{O}_{2}$ A-band ascent and descent 

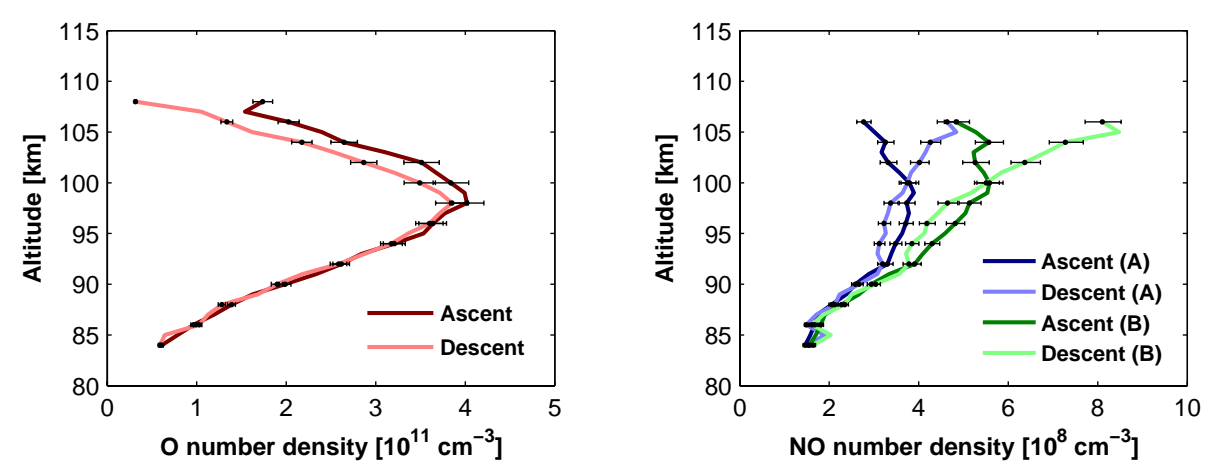

Fig. 4. Left panel: the retrieved $\mathrm{O}$ profiles from the $\mathrm{O}_{2}$ A-band ascent and descent emission measurements. The error bars show the possible errors in the retrieval due to the uncertainties of the rate coefficients. Right panel: the inferred NO concentrations plotted for the "case A" (with a temperature independent two-body reaction) in blue colours and "case B" (with a temperature dependent two-body reaction) in green colours. The darker colour profiles are the ascent measurements and the lighter colour profiles are the descent measurements. The error bars show also here the possible errors in the retrieval due to the uncertainties of the rate coefficients in the $\mathrm{O}$ retrieval.

emission measurements are shown in the left panel of Fig. 4. The derived peak $\mathrm{O}$ concentrations during ascent and descent are $3.8 \times 10^{11} \mathrm{~cm}^{-3}$ and $4.0 \times 10^{11} \mathrm{~cm}^{-3}$, respectively, both at an altitude of about $98 \mathrm{~km}$. The error bars show the possible errors in the retrieval due to the uncertainties of the rate coefficients. In the right panel the inferred NO concentrations are plotted for the "case A" (temperature independent two-body reaction) in blue colours and "case B" (temperature dependent two-body reaction) in green colours. It can be seen that the "case B" NO densities (ascent and descent) are significantly larger at all altitudes. The peak NO concentrations during ascent are $3.9 \times 10^{8} \mathrm{~cm}^{-3}$ and $5.8 \times 10^{8} \mathrm{~cm}^{-3}$ at an altitude of about $99 \mathrm{~km}$ for "case A" and "case B", respectively. The error bars show also here the possible errors in the retrieval due to the uncertainties of the rate coefficients in the $\mathrm{O}$ retrieval. The sensitivity of the $\mathrm{O}$ and $\mathrm{NO}$ retrieval to atmospheric temperature and density variability can be estimated using the temperature climatology of Rauthe et al. (2008) and the atmospheric density of Rapp et al. (2001). At the peaks of the $\mathrm{O}$ and NO profiles the temperature variability in December is typically $\pm 6 \mathrm{~K}$ which yields a variability in the $\mathrm{O}$ and $\mathrm{NO}$ densities of $\pm 4 \%$ and $\pm 2 \%$, respectively. A temperature increase results in an increase in both $\mathrm{O}$ and $\mathrm{NO}$ densities. At the same altitude the atmospheric density variability is typically $\pm 15 \%$ for the autumn months (September to October) resulting in a variability in the $\mathrm{O}$ density of $\pm 12 \%$, but no change in the NO peak density. Both the $\mathrm{O}$ and NO profiles are shifted by $\pm 1 \mathrm{~km}$ due to the atmospheric density variability. While the $\mathrm{O}$ profile is shifted downwards by an increase in the atmospheric density, the NO profile is shifted upwards.

The advantage of this photometric technique is its simplicity. The disadvantage is the limited accuracy due to uncertainties of the underlying chemical rate coefficients and that especially the $\mathrm{NO}_{2}$ continuum measurement is limited to auroral-free conditions. The geomagnetic conditions the days before and during the launch of ECOMA7 were very calm and there are no indications of any contaminating auroral emissions in either of the two wavelength regions defined by the photometer passbands.

Very recently, Evans et al. (2010) reported on the discovery of the orange bands of excited $\mathrm{FeO}$ in the low latitude nightglow spectrum. The excited $\mathrm{FeO}$ is the result of the reaction between $\mathrm{Fe}$ and $\mathrm{O}_{3}$ and the wavelength region covered by the $\mathrm{FeO}$ emission is from $\sim 520 \mathrm{~nm}$ to longer than $700 \mathrm{~nm}$, i.e. it coincides spectrally with the $\mathrm{NO}_{2}$ continuum emission. However, because of the chemistry involved in the production of the two species, the altitudes of emission are separated with the $\mathrm{NO}_{2}$ continuum emission peaking some 5-10 km higher than the FeO. Evans et al. (2010) restricted the observations to latitudes equatorward of $40^{\circ}$ where the $\mathrm{NO}_{2}$ continuum emission is believed to be only a minor contributor and the $\mathrm{FeO}$ emission to be the major contributor to the nightglow continuum. At auroral latitudes it is more likely the opposite situation, with the $\mathrm{NO}_{2}$ continuum emission as the major contributor. The photometric measurement at $540( \pm 8) \mathrm{nm}$ is at the very edge of the short wavelength tail of the $\mathrm{FeO}$ emission spectrum and it is not likely that the measurement is contaminated. For future studies of the $\mathrm{NO}_{2}$ continuum, it is however recommended to go to slightly shorter wavelengths to avoid auroral and chemiluminescent emissions as much as possible.

Another contaminating emission that could potentially influence the measurement is an optical emission produced by the interaction between the rocket payload and the atmosphere known as vehicle induced emissions, or payload glow. This emission is more commonly a problem at longer wavelengths in the near IR spectral region but can occur at wavelengths down to the UV. However, looking at Fig. 2 and comparing the ascent and descent radiance profiles there is no evidence of such aerodynamically induced emissions at either of the two spectral regions. 


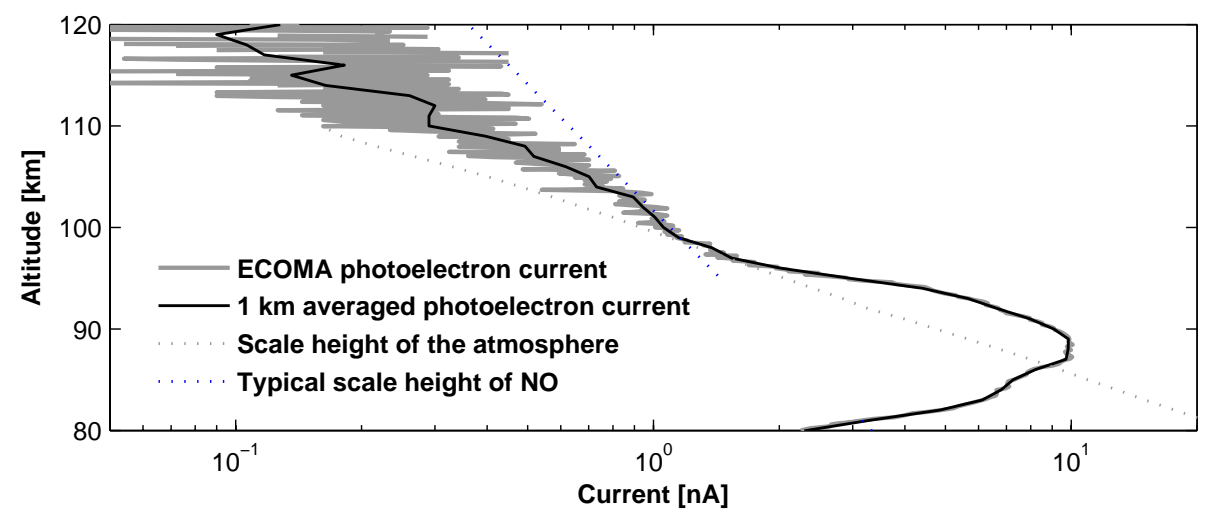

Fig. 5. The photoelectron measurement by the ECOMA detector on the ascent part of the flight. The solid grey profile is the complete data while the solid black line is the $1 \mathrm{~km}$ interval averaged data. The dotted grey and blue lines show the decrease of the neutral atmosphere and NO densities with increasing altitude indicating their scale heights of $\sim 5 \mathrm{~km}$ and $\sim 18 \mathrm{~km}$, respectively. Photoelectrons from the photoionization of $\mathrm{NO}$ are thought to dominate the signal above $\sim 95 \mathrm{~km}$, i.e. above the main meteoric smoke particle layer.

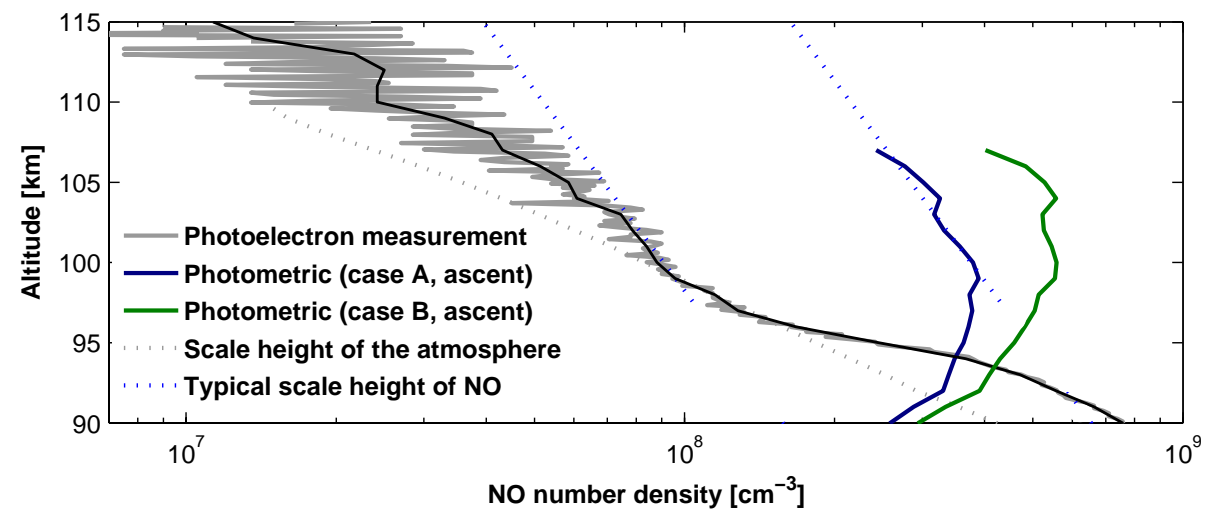

Fig. 6. The solid grey profile is the NO concentration inferred from the photoelectron measurement by the ECOMA detector (the solid black profile is the $1 \mathrm{~km}$ interval averaged inferred NO concentration). The solid blue and green profiles are the "case A" and "case B" NO concentrations inferred from the photometric study on the ascent part of the flight, respectively. The dotted grey line is the scaled atmospheric density showing the decrease of the neutral atmosphere with increasing altitude (scale height $\sim 5 \mathrm{~km}$ around $105 \mathrm{~km}$ ) while the two dotted blue lines show the typical decrease of the NO concentration with altitude above the peak (typical scale height $\sim 18 \mathrm{~km}$ ).

\subsection{The ECOMA measurements}

As mentioned in the introduction, the ECOMA instrument measures meteoric smoke particles by actively photoionizing them with a xenon flash lamp followed by detection of the resulting photoelectrons (Rapp and Strelnikova, 2009). The instrument has two measurement channels: one slow for the continuous charge signal from the naturally charged MSPs that are heavy enough to reach all the way to the detector electrode, and one fast for the very short charge pulses due to the photoelectrons excited by the UV flash. It is believed that not only MSPs are photoionized by the UV flash, but also other species of which NO is the top candidate (Rapp and Strelnikova, 2009). The photons from the flash lamp have a broad spectrum with a maximum energy of $11.2 \mathrm{eV}$, which is enough to ionize NO. Hence, above $\sim 85-90 \mathrm{~km}$, the measured charge signal by the fast channel is most likely "contaminated" by photoelectrons from the photoionization of NO. The solid grey profile in Fig. 5 is the photoelectron measurement made by the ECOMA detector (the black profile is the $1 \mathrm{~km}$ interval averaged photoelectron data). The dotted grey profile indicate the scale height of the neutral atmosphere in this altitude range (September-October climatology) while the dotted blue profile indicate the typical scale height of NO above the NO peak at 100-105 km (e.g. Barth, 1996). At altitudes above the peak of the MSP layer at $\sim 90 \mathrm{~km}$, the MSP number density is expected to show a sharp decrease with increasing altitude with a scale height on the order of 1-2 km or less (Megner et al., 2008), i.e. significantly smaller than that of the photoelectron current profile, the neutral atmosphere $(\sim 5 \mathrm{~km})$ and a typical NO profile $(\sim 18 \pm 5 \mathrm{~km})$. Rapp and Strelnikova (2009) estimated that the maximum photocurrent due to the photoionization of a species by the flash lamp could be calculated as 


$$
\begin{aligned}
I_{\max } & =\left(\int_{2.5 \mathrm{~cm}}^{v_{\mathrm{e}} \cdot \Delta t} \int_{110 \mathrm{~nm}}^{h c} / W_{i} \frac{d F}{d \lambda} \cdot \sigma_{i}(\lambda) \cdot P \cdot n_{i} \cdot d \lambda \cdot d l\right) \cdot \frac{e}{\Delta t} \\
& \approx\left(F_{\mathrm{tot}}^{i} \cdot \bar{\sigma}_{i} \cdot n_{i} \int_{2.5 \mathrm{~cm}}^{v_{\mathrm{e}} \cdot \Delta t} P \cdot d l\right) \cdot \frac{e}{\Delta t}
\end{aligned}
$$

where $v_{\mathrm{e}}$ is the velocity of the photoelectron, $\Delta t=10 \mu \mathrm{s}$ is the sampling interval in the fast data channel, $h$ is Planck's constant, and $c$ is the speed of light. $d F / d \lambda$ is the number of photons per wavelength interval emitted in one flash, $P=S /\left(4 \pi l^{2}\right)$ is the probability that the photoelectron is emitted towards the detector electrode with area $S$, and $l$ is the distance from the particle detector. $W_{i}$ is the threshold energy for the photoionization of species $i, n_{i}$ is the number density of species $i, \sigma_{i}(\lambda)$ is the cross section for photoionization of species $i$ at wavelength $\lambda$, and $e$ is the charge of an electron. For the analysis, it is assumed that the integral over the wavelength may be approximated as $F_{\text {tot }}^{i} \cdot \overline{\sigma_{i}}$ where $F_{\text {tot }}^{i}$ is the total number of photons emitted in one flash with an energy larger than $W_{i}$ and $\overline{\sigma_{i}}$ is the average cross section over the corresponding wavelength interval. Determining $F_{\text {tot }}^{i}$, using the cross section for the photoionization of NO from Watanabe et al. (1953), and calculating the probability of a photoelectron to reach the detector surface within one $10 \mu$ s sampling interval, the maximum photocurrent due to the photoionization of $\mathrm{NO}$ (Eq. 7) can be expressed as

$$
I_{\max }=1.2 \times 10^{-8} \cdot[\mathrm{NO}] \mathrm{nA} .
$$

Considering the ECOMA photoelectron measurement it is possible that photoelectrons from the photoionization of $\mathrm{FeO}$ could contribute to the measured photocurrent as its photoionization threshold is $8.56 \mathrm{eV}$ (Metz et al., 2005). However, the mesospheric NO concentration is significantly larger than the $\mathrm{FeO}$ concentration $\left(\sim 100-1000 \mathrm{~cm}^{-3}\right.$ or a factor of $\sim 10-100$ less than the Fe concentration at the peak around $80-85 \mathrm{~km}$ (Kane and Gardner, 1993)). Hence, it can be concluded that there should be no contribution to the measured photoelectron current due to photoelectrons from the photoionization of $\mathrm{FeO}$.

\section{Discussion and conclusion}

Considering the uncertainties in the rate coefficients and excitation parameters in the nightglow $\mathrm{O}$ retrieval, the possible temperature dependence of the two-body reaction path (Reaction R2, Eq. 2), and the variability of the neutral atmosphere density and temperature, the peak NO number density inferred from the photometric measurements on ECOMA7 is between $3.7 \times 10^{8} \mathrm{~cm}^{-3}$ and $6.0 \times 10^{8} \mathrm{~cm}^{-3}$. This is in agreement with other measurements at high latitudes reported from both rockets (Witt et al., 1981; Iwagami and Ogawa,
1980; McDade et al., 1986a) and satellites (Stevens et al., 1997; von Savigny et al., 1999; Barth et al., 2001; Gardner et al., 2007; Kerzenmacher et al., 2008; Gattinger et al., 2010; Sheese et al., 2011). Using different techniques (NO $\gamma$-band UV dayglow, $\mathrm{NO}_{2}$ continuum nightglow $+\mathrm{O}$, solar occultation in the IR, NO $5.3 \mu \mathrm{m}$ emission), these measurements show peak NO number densities of $1-7 \times 10^{8} \mathrm{~cm}^{-3}$ in the auroral region. At low latitudes the peak number densities are in general an order of magnitude smaller than at high latitudes, which is consistent with the production and loss mechanisms at high and low latitudes.

The NO number densities inferred from the simultaneous photoelectron measurement by the ECOMA detector above the main MSP layer do not, however, agree with the densities inferred from the photometric measurements. Figure 6 shows that the NO density inferred from the photoelectron current using Eqs. (7) and (8) is significantly smaller than those inferred from the photometers in the $95-110 \mathrm{~km}$ altitude range. The solid grey profile in Fig. 6 is the NO concentration inferred from the photoelectron measurement by the ECOMA detector. The solid blue and green profiles are the "case A" and "case B" NO concentrations inferred from the photometric study on the ascent part of the flight, respectively. As in Fig. 5, the dotted grey line is the scaled atmospheric density showing the decrease of the neutral atmosphere with increasing altitude (scale height $\sim 5 \mathrm{~km}$ around $105 \mathrm{~km}$ ) while the two dotted blue lines show the typical decrease of the NO concentration with altitude above the peak (typical scale height $\sim 18 \pm 5 \mathrm{~km}$ ). A scale height of $18 \mathrm{~km}$ is also what we see for the "case A" NO density profile at $100-105 \mathrm{~km}$. Due to the low emission rates of the $\mathrm{O}_{2}$ A-band and $\mathrm{NO}_{2}$ continuum above the main emission layer it was not feasible to retrieve $\mathrm{O}$ and NO number densities above $\sim 107 \mathrm{~km}$. It is possible that the scale height of the NO profile becomes smaller above $\sim 105 \mathrm{~km}$ as is indicated by both "case A" and "case B" NO profiles. The scale height of the photoelectron measurement above $\sim 98 \mathrm{~km}$ is significantly larger than the expected scale height of the MSP profile but smaller than the typical $18 \mathrm{~km}$ scale height of NO. Thus, photoelectrons from NO is the major, but not the only, contributor to the photoelectron measurement above $100 \mathrm{~km}$.

A large part of the discrepancy in the number densities seen in Fig. 6 is most likely due to the simple approximation of the factor $P$ in Eq. (7), i.e. the probability that a photoelectron will hit the detector surface. In addition, Eq. (7) uses a spectrum from a different flashlamp than the one that was launched. A characterization of spectra from different flashlamps has shown that the differences between them can be up to $30 \%$. The currently used conversion factor in Eq. (8) must be considered as an upper estimate and the actual value is most likely a significant factor smaller. The density inferred from the photoelectron measurement is a factor of 5 smaller than the "case A" NO density (blue profile in Fig. 6) and a factor of 9 smaller than the "case B" NO density (green profile). To properly quantify the contribution of photoelectrons 
from the photoionization of NO to that of the MSPs, or use the ECOMA photoelectron measurements to derive NO number densities, Eq. (7), and in particular the probability factor $P$, must be re-evaluated. The possibility that payload charging may influence the detection probability by affecting the photoelectrons must also be considered.

Based mainly on the current uncertainties in Eq. (7), and to some extent the fact that both the local and ground based atmospheric density and temperature measurements failed, we cannot say anything qualitative about a possible temperature dependence in the two-body reaction path of the $\mathrm{NO}+\mathrm{O}$ air afterglow reaction that give rise to the $\mathrm{NO}_{2}$ nightglow continuum.

$\mathrm{NO}$ is an important species in the atmosphere and it is desirable to have measurements with high spatial resolution. The photoionization technique is potentially very useful since it seems to be the only technique that can be used both daytime and nighttime and at the same time provide high spatial resolution. Optical techniques, on the other hand, only work either nighttime $\left(\mathrm{NO}_{2}\right.$ continuum) or daytime ( $\mathrm{NO}$ $\gamma$-band resonance fluorescence). The photoionization technique could thus provide a way to cross-compare different optical techniques between daytime and nighttime. For this purpose, the photoionization technique does not even need to provide an absolute measurement.

In this paper we have presented two techniques for nighttime NO measurements. We have inferred $\mathrm{NO}$ densities from photometric measurements of the $\mathrm{O}_{2}$ A-band and the $\mathrm{NO}_{2}$ continuum nightglow emissions, but there are difficulties in the interpretation of the photoelectron current in detecting NO with the ECOMA detector. Both work in principle but there are uncertainties and currently we do not have quantitative agreement between them.

Acknowledgements. The ECOMA project was sponsored by the German Space Center under DLR-grants 50OE0301 and 50OE0801. The Swedish contribution to ECOMA was made possible by the support from the Swedish National Space Board.

Guest Editor U.-P. Hoppe thanks two anonymous referees for their help in evaluating this paper.

\section{References}

Bailey, S. M., Barth, C. A., and Solomon, S. C.: A model of nitric oxide in the lower thermosphere, J. Geophys. Res., 107, 22, doi:10.1029/2001JA000258, 2002.

Barth, C. A.: Rocket measurement of the nitric oxide dayglow, J. Geophys. Res., 69, 3301-3303, 1964.

Barth, C. A.: Nitric oxide in the lower thermosphere, Planet. Space Sci., 40, 315-336, 1992.

Barth, C. A.: Reference models for thermospheric nitric oxide, 1994, Adv. Space Res., 18, 179-208, 1996.

Barth, C. A., Baker, D. N., Mankoff, K. D., and Bailey, S. M.: The northern auroral region as observed in nitric oxide, Geophys. Res. Lett., 28, 1463-1466, 2001.
Barth, C. A., Lu, G., and Roble, R. G.: Joule heating and nitric oxide in the thermosphere, J. Geophys. Res., 114, A05301, doi:10.1029/2008JA013765, 2009.

Becker, K. H., Groth, W., and Thran, D.: The mechanism of the airafterglow $\mathrm{NO}+\mathrm{O} \rightarrow \mathrm{NO}_{2}+h v$, Chem. Phys. Lett., 15, 215-220, 1972.

Enell, C.-F., Hedin, J., Stegman, J., Witt, G., Friedrich, M., Singer, W., Baumgarten, G., Kaifler, B., Hoppe, U.-P., Gustavsson, B., Brändström, U., Khaplanov, M., Kero, A., Ulich, T., and Turunen, E.: The Hotel Payload 2 campaign: Overview of NO, O and electron density measurements in the upper mesosphere and lower thermosphere, J. Atmos. Sol.-Terr. Phys., 73, 2228-2236, doi:10.1016/j.jastp.2011.01.001, 2011.

Evans, W. F. J., Gattinger, R. L., Slanger, T. G., Saran, D. V., Degenstein, D. A., and Llewellyn, E. J: Discovery of the FeO orange bands in the terrestrial night airglow spectrum obtained with OSIRIS on the Odin spacecraft, Geophys. Res. Lett., 37, L22105, doi:10.1029/2010GL045310, 2010.

Fentzke, J. T., Janches, D., Strelnikova, I., and Rapp, M.: Meteoric smoke particles derived using dual beam Arecibo UHF observations of D-region spectra during different seasons, J. Atmos. Sol.-Terr. Phys., 71, 1982-1991, 2009.

Funke, B., Lópes-Puertas, M., and Gil-Lópes, S.: Downward transport of upper atmospheric $\mathrm{NO}_{\mathrm{x}}$ into the polar stratosphere and lower mesosphere during the Antarctic 2003 and Arctic 2002/2003 winters, J. Geophys. Res., 110, D24308, doi:10.1029/2005JD006463, 2005.

Gabrielli, P., Barbante, C., Plane, J. M. C., Varga, A., Hong, S.,Cozzi, G., Gaspari, V., Planchon, F. A. M., Cairns, W., Ferrari, C., Crutzen, P., Cescon, P., and Boutron, C. F.: Meteoric smoke fallout over the Holocence epoch revealed by iridium and platinum in Greenland ice, Nature, 432, 1011-1014, doi:10.1038/nature03137, 2004.

Gardner, J. L., Funke, B., Mlynczak, M. G., López-Puertas, M., Martin-Torres, F. J., Russell III, J. M., Miller, S. M., Sharma, R. D., and Winick, J. R.: Comparison of nighttime nitric oxide $5.3 \mu \mathrm{m}$ emissions in the thermosphere measured by MIPAS and SABER, J. Geophys. Res., 112, A10301, doi:10.1029/2006JA011984, 2007.

Gattinger, R. L., McDade, I. C., Alfaro Suzán, A. L., Boone, C. D., Walker, K. A., Bernath, P. F., Evans, W. F. J., Degenstein, D. A., Yee, J.-H., Sheese, P., and Llewellyn, E. J.: $\mathrm{NO}_{2}$ air afterglow and $\mathrm{O}$ and NO densities from Odin-OSIRIS night and ACE-FTS sunset observations in the Antarctic MLT region, J. Geophys. Res., 115, D12301, doi:10.1029/2009JD013205, 2010.

Greer, R. G. H., Murtagh, D. P., McDade, I. C., Dickinson, P. H. G., Thomas, L., Jenkins, D. B., Stegman, J., Llewellyn, E. J., Witt, G., Mackinnon, D. J., and Williams, E. R.: ETON 1: A database pertinent to the study of energy transfer in the oxygen nightglow, Planet. Space Sci., 34, 771-788, 1986.

Havnes, O., Trim, J., Blix, T., Mortensen, W., Næsheim, L. I., Thrane, E., and Tønnesen, T.: First detection of charged dust in the Earth's mesosphere, J. Geophys. Res., 101, 10839-10847, 1996.

Hedin, J., Gumbel, J., and Rapp, M.: On the efficiency of rocketborne particle detection in the mesosphere, Atmos. Chem. Phys., 7, 3701-3711, doi:10.5194/acp-7-3701-2007, 2007.

Hedin, J., Gumbel, J., Stegman, J., and Witt, G.: Use of $\mathrm{O}_{2}$ airglow for calibrating direct atomic oxygen measurements from sound- 
ing rockets, Atmos. Meas. Tech., 2, 801-812, doi:10.5194/amt2-801-2009, 2009.

Hunten, D. M., Turco, R. P., and Toon, O. B.: Smoke and dust particles of meteoric origin in the mesosphere and thermosphere, J. Atmos. Sci., 37, 1342-1357, 1980.

Iwagami, N. and Ogawa, T.: An Antarctic NO density profile deduced from the gamma band airglow, Planet. Space Sci., 28, 867$873,1980$.

Kane, T. J. and Gardner, C. S.: Structure and seasonal variability of the nighttime mesospheric Fe layer at midlatitudes, J. Geophys. Res., 98, 16875-16886, 1993.

Kaplan, J.: Nitric oxide in the Earth's upper atmosphere, Nature, $144,152,1939$.

Kerzenmacher, T., Wolff, M. A., Strong, K., Dupuy, E., Walker, K. A., Amekudzi, L. K., Batchelor, R. L., Bernath, P. F., Berthet, G., Blumenstock, T., Boone, C. D., Bramstedt, K., Brogniez, C., Brohede, S., Burrows, J. P., Catoire, V., Dodion, J., Drummond, J. R., Dufour, D. G., Funke, B., Fussen, D., Goutail, F., Griffith, D. W. T., Haley, C. S., Hendrick, F., Höpfner, M., Huret, N., Jones, N., Kar, J., Kramer, I., Llewellyn, E. J., López-Puertas, M., Manney, G., McElroy, C. T., McLinden, C. A., Melo, S., Mikuteit, S., Murtagh, D., Nichitiu, F., Notholt, J., Nowlan, C., Piccolo, C., Pommereau, J.-P., Randall, C., Raspollini, P., Ridolfi, M., Richter, A., Schneider, M., Schrems, O., Silicani, M., Stiller, G. P., Taylor, J., Tétard, C., Toohey, M., Vanhellemont, F., Warneke, T., Zawodny, J. M., and Zou, J.: Validation of $\mathrm{NO}_{2}$ and NO from the Atmospheric Chemistry Experiment (ACE), Atmos. Chem. Phys., 8, 5801-5841, doi:10.5194/acp-8-5801-2008, 2008.

Kockarts, G.: Nitric oxide cooling in the terrestrial thermosphere, Geophys. Res. Lett., 7, 137-140, doi:10.1029/GL007i002p00137, 1980.

Leinert, Ch., Bowyer, S., Haikala, L. K., Hanner, M. S., Hauser, M. G., Levasseur-Regourd, A.-Ch., Mann, I., Mattila, K., Reach, W. T., Schlosser, W., Staude, H. J., Toller, G. N., Weiland, J. L., Weinberg, J. L., and Witt, A. N.: The 1997 reference of diffuse night sky brightness, Astron. Astrophys. Suppl. Ser., 127, 1-99, 1998.

López-Puertas, M. and Taylor, F. W.: NO $5.3 \mu \mathrm{m}$ cooling, in NonLTE Radiative Transfer in the Atmosphere, 343-344, World Scientific Publishing Co. Pte. Ltd., Singapore, 2001.

Love, S. G. and Brownlee, D. E.: A direct measurement of the terrestrial mass accretion rate of cosmic dust, Science, 262, 550553, 1993

Mathews, J. D., Janches, D., Meisel, D. D., and Zhou, Q. H.: The micrometeroid mass flux into the upper atmosphere: Arecibo results and a comparison with prior estimates, Geophys. Res. Lett., 28, 1929-1932, 2001.

McDade, I. C., Llewellyn, E. J., Greer, R. G. H., and Murtagh, D. P.: ETON 3: Altitude profiles of the nightglow continuum at green and near infrared wavelengths, Planet. Space Sci., 34, 801-810, 1986a.

McDade, I. C., Murtagh, D. P., Greer, R. G. H., Dickinson, P. H. G., Witt, G., Stegman, J., Llewellyn, E. J., Thomas, L., and Jenkins, D. B.: ETON 2: Quenching parameters for the proposed precursors of $\mathrm{O} 2\left(\mathrm{~b}^{1} \sum_{g}^{+}\right)$and $\mathrm{O}\left({ }^{1} \mathrm{~S}\right)$ in the terrestrial nightglow, Planet. Space Sci., 34, 789-800, 1986b.

Megner, L., Siskind, D. E., Rapp, M., and Gumbel, J.: Global and temporal distribution of meteoric smoke: A two- dimensional simulation study, J. Geophys. Res., 113, D03202, doi:10.1029/2007JD009054, 2008.

Meriwether Jr., J. W.: A review of the photochemistry of selected nightglow emissions from the mesopause, J. Geophys. Res., 94, 14629-14646, 1989.

Metz, R. B., Nicolas, C., Ahmed, M., and Leone, S. R.: Direct determination of the ionization energies of $\mathrm{FeO}$ and $\mathrm{CuO}$ with VUV radiation, J. Chem. Phys., 123, 114313, doi:10.1063/1.2032947, 2005.

Murtagh, D. P.: A self-consistent model of the most common nightglow emissions, Proceedings of the Ninth ESA/PAC Symposium on European Rocket and Balloon Programmes and related research (ESA SP-291), Lahnstein, Germany, 3-7 April, 1989.

Nicolet, M.: Contribution à l'étude de la structure de l'ionosphère, Institut royal météorologique de Belgique, Mémoires, 19, 124, 1945.

Picone, J. M., Hedin, A. E., Drob, P., and Aikin, A. C.: NRLMSISE-00 empirical model of the atmosphere: Statistical composition and scientific issues, J. Geophys. Res., 107, 1468, doi:10.1029/2002JA009430, 2002.

Plane, J. M. C.: Atmospheric chemistry of meteoric metals, Chem. Rev., 103, 4963-4984, 2003.

Plane, J. M. C.: A time-resolved model of the mesospheric Na layer: constraints on the meteor input function, Atmos. Chem. Phys., 4, 627-638, doi:10.5194/acp-4-627-2004, 2004.

Randall, C. E., Harvey, V. L., Siskind, D. E., France, J., Bernath, P. F., Boone, C. D., and Walker, K. A.: $\mathrm{NO}_{\mathrm{X}}$ descent in the Arctic middle atmosphere in early 2009, Geophys. Res. Lett., 36, L18811, doi:10.1029/2009GL039706, 2009.

Rapp, M. and Lübken, F.-J.: Modelling of particle charging in the polar summer mesosphere: Part 1. General results, J. Atmos. Sol.-Terr. Phys., 63, 759-770, 2001.

Rapp, M. and Strelnikova, I.: Measurements of meteor smoke particles during the ECOMA-2006 campaign: 1. Particle detection by active photoionization, J. Atmos. Sol.-Terr. Phys., 71, 477-485, 2009.

Rapp, M. and Thomas, G. E.: Modeling the microphysics of mesospheric ice particles: Assessment of current capabilities and basic sensitivities, J. Atmos. Sol.-Terr. Phys., 68, 715-744, 2006.

Rapp, M., Gumbel, J., and Lübken, F.-J.: Absolute density measurements in the middle atmosphere, Ann. Geophys., 19, 571-580, doi:10.5194/angeo-19-571-2001, 2001.

Rapp, M., Strelnikova, I., and Gumbel, J.: Meteoric smoke particles: evidence from rocket and radar techniques, Adv. Space Res., 40, 809-817, doi:10.1016/j.asr.2006.11.021, 2007.

Rapp, M., Strelnikova, I., Strelnikov, B., Hoffmann, P., Friedrich, M., Gumbel, J., Megner, L., Hoppe, U.-P., Robertson, S., Knappmiller, S., Wolff, M., and Marsh, D. R.: Rocket-borne in situ measurements of meteor smoke: Charging properties and implication for seasonal variation, J. Geophys. Res., 115, D00I16, doi:10.1029/2009JD012725, 2010.

Rapp, M., Plane, J. M. C., Strelnikov, B., Stober, G., Ernst, S., Hedin, J., Friedrich, M., and Hoppe, U.-P.: In-situ observations of meteor smoke particles (MSP) during the Geminids 2010: Constraints on MSP size, work function, and composition, Ann. Geophys., in press, 2012.

Rauthe, M., Gerding, M., and Lübken, F.-J.: Seasonal changes in gravity wave activity measured by lidars at mid-latitudes, Atmos. Chem. Phys., 8, 6775-6787, doi:10.5194/acp-8-6775-2008, 
2008.

Rosinski, J. and Snow, R. H.: Secondary particulate matter from meteor vapors, J. Meteorol. 18, 736-745, 1961.

Rusch, D. W., Gérard, J.-C., Solomon, Solomon, S., Crutzen, P. J., and Reid, G. C.: The effect of particle precipitation events on the neutral and ion chemistry of the middle atmosphere - I. Odd nitrogen, Planet. Space Sci., 29, 767-774, 1981.

Sharp, W. E.: $\mathrm{NO}_{2}$ continuum in the aurora, J. Geophys. Res., 83, 4373-4376, 1978.

Sharp, W. E.: On the temperature dependence of the reaction $\mathrm{NO}+\mathrm{O} \rightarrow \mathrm{NO}_{2}^{*}$, Planet. Space Sci., 32, 257-260, 1984.

Sheese, P. E., Gattinger, R. L., Llewellyn, E. J., Boone, C. D., and Strong, K.: Nighttime nitric oxide densities in the southern hemisphere mesosphere-lower thermosphere, Geophys. Res. Lett., 38, L15812, doi:10.1029/2011GL048054, 2011.

Siskind, D. E., Nedoluha, G. E., randall, C. E., Fromm, M., and Russell III, J. M.: An assessment of southern hemisphere stratospheric $\mathrm{NO}_{\mathrm{x}}$ enhancements due to transport from the upper atmosphere, Geophys. Res. Lett., 27, 329-332, 2000.

Solomon, S., Crutzen, P, J., and Roble, R. G.: Photochemical coupling between the thermosphere and the lower atmosphere 1 . Odd nitrogen from 50 to $120 \mathrm{~km}$, J. Geophys. Res., 87, 7206$7220,1982$.

Stevens, M. H., Conway, R. R., Cardon, J. G., and Russell III, J. M.: MAHRSI observations of nitric oxide in the mesosphere and thermosphere, Geophys. Res. Lett., 24, 3213-3216, 1997.

Strelnikova, I., Rapp, M., Raizada, S., and Sulzer, M.: Meteor smoke particle properties derived from Arecibo incoherent scatter radar observations, Geophys. Res. Lett., 34, L15815, doi:10.1029/2007GL030635, 2007.

Strelnikova, I., Rapp, M., Strelnikov, B., Baumgarten, G., Brattli, A., Svenes, K., Hoppe, U.-P., Friedrich, M., Gumbel, J., and Williams, B.: Measurements of meteor smoke particles during the ECOMA-2006 campaign: 2. Results, J. Atmos. Sol.-Terr. Phys., 71, 486-496, 2009.
Strobel, D. F.: Odd Nitrogen in the Mesosphere, J. Geophys. Res., 76, 8384-8393, 1971.

Summers, M. E., Conway, R. R., Englert, C. R., Siskind, D. E., Stevens, M. H., Russel, J. M., Gordley, L. L., and McHugh, M. J.: Discovery of a water vapor layer in the arctic summer mesosphere: Implications for polar mesospheric clouds, Geophys. Res. Lett., 28, 3601-3604, 2001.

Thorne, R. M.: The importance of energetic particle precipitation on the chemical composition of the middle atmosphere, Pageogh, 118, Birkhäuser Verlag, Basel, 1980.

Voigt, C., Schlager, H., Luo, B. P., Dörnbrack, A., Roiger, A., Stock, P., Curtius, J., Vössing, H., Borrmann, S., Davies, S., Konopka, P., Schiller, C., Shur, G., and Peter, T.: Nitric Acid Trihydrate (NAT) formation at low NAT supersaturation in Polar Stratospheric Clouds (PSCs), Atmos. Chem. Phys., 5, 13711380, doi:10.5194/acp-5-1371-2005, 2005.

von Savigny, C. H. A., McDade, I. C., Shepherd, G. G., and Rochon, Y.: Lower thermospheric nitric oxide concentrations derived from WINDII observations of the green nightglow continuum at $553.1 \mathrm{~nm}$, Ann. Geophys., 17, 1439-1446, doi:10.1007/s00585999-1439-9, 1999.

von Zahn, U.: The total mass flux of meteoroids into the Earth's upper atmosphere, Proceedings from the 17th ESA Symposium on European Rocket and Balloon Programmes and Related Research (ESASP-590), 33-39, 2005.

Watanabe, K., Marmo, F. F., and Inn, E. C. Y.: Photoionization cross section of nitric oxide, Phys. Rev., 91, 1155-1158, 1953.

Whytock, D. A., Michael, J. V., and Payne, W. A.: Absolute rate constants for $\mathrm{O}+\mathrm{NO}+\mathrm{N}_{2} \rightarrow \mathrm{NO}_{2}+\mathrm{N}_{2}$ from $217-500 \mathrm{~K}$, Chem. Phys. Lett., 42, 466-471, 1976.

Witt, G., Rose, J., and Llewellyn, E. J.: The airglow continuum at high latitudes - an estimate of the NO concentration, J. Geophys. Res., 86, 623-628, 1981. 